\title{
State of the Art Hollow Fiber Supported Liquid Membrane on Pd (II) Separation from Wastewater Using Alamine 336
}

\author{
Kraiwith Wongkaew, Natchanun Leepipatpiboon, and Ura Pancharoen
}

\begin{abstract}
A hollow fiber supported liquid membrane (HFSLM), having unique characteristics in the separation and stripping of trace species from dilute aqueous solutions, was applied to separate trace Pd(II) of approximately 1 ppm from wastewater. Optimum values of the parameters influencing the extraction and stripping of Pd(II) were investigated i.e. types of extractants (Alamine 336 and Aliquat 336), types of stripping agents $\left(\mathrm{H}_{2} \mathrm{SO}_{4}, \mathrm{HCl}, \mathrm{NH}_{2} \mathrm{CSNH}_{2}, \mathrm{NH}_{4} \mathrm{Cl}\right.$ and a mixture of $\mathrm{NH}_{2} \mathrm{CSNH}_{2}$ and $\mathrm{HCl}$ ), as well as types of diluents. The experimental results indicated that Alamine 336 and a mixture of $\mathrm{NH}_{2} \mathrm{CSNH}_{2}$ and $\mathrm{HCl}$ were the extractant and stripping solution, respectively. Under the most favorable operating conditions, Pd(II) was successfully separated from Pt(IV), $\mathrm{Au}(\mathrm{III}), \mathrm{Cu}(\mathrm{II})$ and $\mathrm{Zn}(\mathrm{II})$. Percentages of $\mathrm{Pd}(\mathrm{II})$ extraction and stripping were achieved reaching $95 \%$ and $88 \%$ respectively. Reproducibility of the HFSLM system was found to be $\pm 2 \%$.
\end{abstract}

Index Terms-Palladium, Alamine 336, Aliquat 336, wastewater, HFSLM.

\section{INTRODUCTION}

Platinum group elements (PGEs) are very expensive, high quality materials and are utilized in industries such as automobiles, petroleum, dental, catalyst, medicine and jewelry. Extraction and recovery of PGMs are difficult and complicated due to their chemical properties and formation of many chemical species in chloride media. Moreover, some platinum group compounds have been reported as potential health risks to humans [1] together with high price levels [2]. Thus, it is very important to investigate the best and most efficient method to recover $\mathrm{Pd}(\mathrm{II})$ from wastewater. Wastewater from the gold-refining process containing $\mathrm{Pd}(\mathrm{II})$ is used as the feed solution [3]. Palladium contaminates the wastewater along with other metal ions such as $\mathrm{Pt}(\mathrm{IV}), \mathrm{Au}(\mathrm{III})$, $\mathrm{Zn}(\mathrm{II})$ and $\mathrm{Cu}(\mathrm{II})$. The concentration of $\mathrm{Pd}(\mathrm{II})$ is about $1 \mathrm{ppm}$ in solution where the original $\mathrm{pH}$ ranges from 6 to 7 .

Conventional methods for the extraction and recovery of palladium from solution are commercially operated e.g. chemical precipitation [4] and solvent extraction [5]. Nevertheless, these methods have some shortcomings [6], [7]. Therefore, HFSLM is recommended due to its various

Manuscript received November 25, 2013; revised January 17, 2014. This work was supported by the Thailand Research Fund through the Royal Golden Jubilee Ph.D. Program (Grant No.PHD/0297/2550).

K. Wongkaew and U. Pancharoen are with the Department of Chemical Engineering, Faculty of Engineering, Chulalongkorn University, Pathumwan Bangkok 10330, Thailand (e-mail: kraiwith2010@ hotmail.com, ura.p@chula.ac.th).

N. Leepipatpiboon is with Chromatography and Separation Research Unit, Department of Chemistry, Faculty of Science, Chulalongkorn University, Patumwan, Bangkok 10330, Thailand (e-mail: natchanun.1@chula.ac.th). advantages compared with conventional methods. In particular, it has low capital and operational costs [8], low energy consumption [9] and high overall separation factors [10]. Moreover, HFSLM is also easily scalable [11] and it can improve the lifetime of the liquid membrane system due to their hydrodynamic characteristics [12]. Many works concerned with simultaneous extraction and recovery of metal ions via HFSLM have recently been reported [13]-[15].

The main objective of this work is to report on the simultaneous extraction and recovery of trace $\mathrm{Pd}(\mathrm{II})$ in chloride media from gold-refining plant wastewater via HFSLM in a single operation. The various effects of the parameters on the percentages of $\mathrm{Pd}(\mathrm{II})$ extraction and stripping such as types of extractants, stripping agents and different diluents were investigated.

\section{THEORY}

\section{A. Transport of Pd(II) across the Liquid Membrane Phase}

The general reaction of Alamine 336 is presented below in two steps: protonation and exchange

Protonation reaction:

$$
\left[R_{3} N\right]_{o r g}+[H A]_{a q} \rightleftharpoons\left[R_{3} N H^{+} A^{-}\right]_{o r g}
$$

Exchange reaction:

$$
\left[R_{3} N H^{+} A^{-}\right]_{\text {org }}+\left[B^{-}\right](a q) \rightleftharpoons\left[R_{3} N H^{+} B^{-}\right]_{\text {org }}+\left[A^{-}\right]_{a q}
$$

Alamine 336 in the presence of the selected diluent is trapped in the hydrophobic micropores of the hollow fibers as the liquid membrane. The feed and stripping solution, having a capacity for palladium ions and the mixture of thiourea and hydrochloric acid utilized as the stripping phase, is normally circulated counter- currently through the tube and shell sides of the hollow fiber module. The transport of palladium ions is illustrated in Fig. 1.

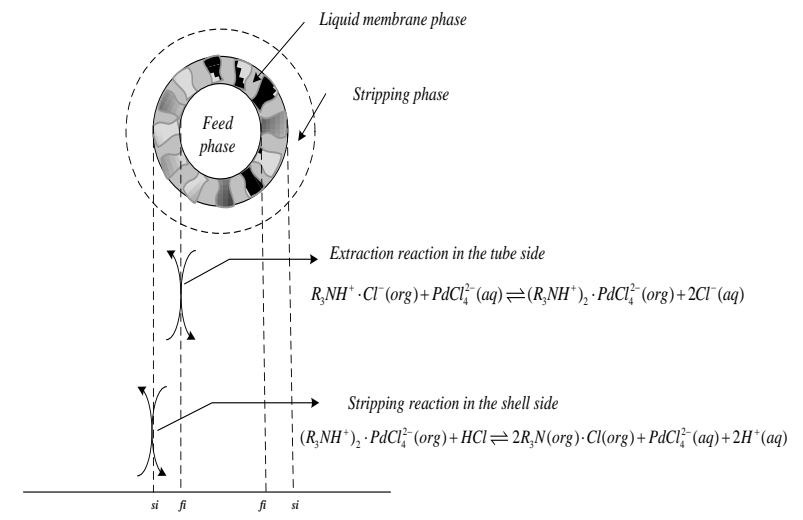

Fig. 1. Transport mechanism of M representing Pd(II) across the liquid membrane phase. 
The tertiary amine forms an amine salt which reacts with an excess amount of hydrochloric acid. Two molecules of amine salt react with palladium tetrachloride complex to form the complex species as shown in Eq (3) [16].

$$
2 \mathrm{R}_{3} \mathrm{NH}^{+} \mathrm{Cl}_{\text {org }}^{-}+\mathrm{PdCl}_{4 a q}^{2-} \rightleftharpoons\left(\mathrm{R}_{3} \mathrm{NH}^{+}\right)_{2} \mathrm{PdCl}_{4 \text { org }}^{2-}+2 \mathrm{Cl}_{\text {aq }}^{-}
$$

\section{B. The Efficiency of Extraction and Stripping}

In this work, the efficiency of $\mathrm{Pd}(\mathrm{II})$ extraction was determined as follows:

$$
\% \text { Extraction }=\frac{[C]_{f, \text { in }}-[C]_{f, \text { out }}}{[C]_{f, \text { in }}} \times 100
$$

The stripping efficiency of $\mathrm{Pd}(\mathrm{II})$ was determined as follows:

$$
\% \text { Stripping }=\frac{[C]_{s, \text { out }}}{[C]_{f, \text { in }}} \times 100
$$

where $[C]_{f, \text { in }}$ and $[C]_{f, \text { out }}$ are the inlet and outlet of feed concentration, respectively; $[C]_{S, \text { out }}$ is the outlet stripping concentration.

\section{EXPERIMENT}

\section{A. Feed and Stripping Solution Preparation}

Alamine 336 (trialkyl (C8-C10) amine) was obtained from Cognis Company. Aliquat 336 is a commercial extractant containing a mixture of $\mathrm{C} 8$ (octyl) and C10 (decyl) chains with $\mathrm{C} 8$ predominating. The $\mathrm{pH}$ of the aqueous feed solution was adjusted by hydrochloric acid from Qrec (USA). All other chemicals such as thiourea $\left(\mathrm{NH}_{2} \mathrm{CSNH}_{2}\right)$ from RFLC (New Zealand), sodium perchlorate $\left(\mathrm{NaClO}_{4}\right)$ from ACROS (USA), sodium hydroxide $(\mathrm{NaOH})$ and sodium thiosulfonate $\left(\mathrm{Na}_{2} \mathrm{~S}_{2} \mathrm{O}_{3}\right)$ from Merck Ltd (Germany) were used as stripping solutions. Hexane, cyclohexane, benzene, 1, 2-dichloromethane and chloroform without further purification, supplied by Sigma-Aldrich, were used as diluents. All substances used were of analytical grade. Doubly deionized water was used throughout the experiments.

The wastewater from the gold-refining plant containing several metal ions as shown in Table I with the original $\mathrm{pH}$ value (6-7) was used as feed solution.

TABLE I: THE COMPOSITIONS OF GOLD-REFINING WASTEWATER

\begin{tabular}{cc}
\hline Compositions & Concentration (ppm) \\
\hline Pt(IV) & 4.578 \\
Pd(II) & 0.876 \\
$\mathrm{Au}($ III) & 0.943 \\
$\mathrm{Cu}(\mathrm{II})$ & 0.549 \\
$\mathrm{Zn}$ (II) & 0.120 \\
\hline
\end{tabular}

\section{B. Apparatus}

A microporous polypropylene hollow fiber module (Liqui-Cel@Extra-Flow 2.5 in. $\times 8$ in. membrane contactor, Hoechst Celanese, USA) was used to prepare the HFSLM system. The specifications of the module are given in Table II.
TABLE II: PHYSICAL CHARACTERISTICS OF THE HOLLOW FIBER MODUlE

\begin{tabular}{ll} 
Characteristics & Descriptions \\
Material & polypropylene \\
Number of fibers & 35,000 \\
Fiber inside diameter $(\mu \mathrm{m})$ & 240 \\
Fiber outside diameter $(\mu \mathrm{m})$ & 300 \\
Effective length $(\mathrm{cm})$ & 19.8 \\
Surface area $\left(\mathrm{m}^{2}\right)$ & 1.4 \\
Area per unit volume $\left(\mathrm{cm}^{2} \mathrm{~cm}^{-3}\right)$ & 29.3 \\
Membrane porosity $(\%)$ & 25 \\
Average pore size $(\mu \mathrm{m})$ & 0.03 \\
Membrane tortuosity & 2.6 \\
Module diameter $(\mathrm{cm})$ & 6.3 \\
Module length $(\mathrm{cm})$ & 20.3 \\
Operating temperature $(\mathrm{C})$ & $1 \sim 60$ \\
\hline
\end{tabular}

\section{Procedure}

The single-module operation in recirculation mode is set up in Fig. 2. At first, the liquid membrane is prepared by mixing Alamine 336 dissolved in kerosene. Then, it is circulated into the lumen and shell sides of the HFSLM system for at least 50 min to ensure the complete soaking of membrane pores. The excessive liquid membrane is completely washed out with sufficient distilled water for $10 \mathrm{~min}$, prior to the pumping of the feed and stripping solutions into the HFSLM system. Thereafter, the feed solution was pumped counter-currently into the lumen side, and at the same time the stripping solution was passed through the shell side. The metal ions from the aqueous solution were transported across the liquid membrane to the stripping phase and were collected in the stripping reservoir. The flow rate for both feed and stripping solutions was kept the same in all experiments.

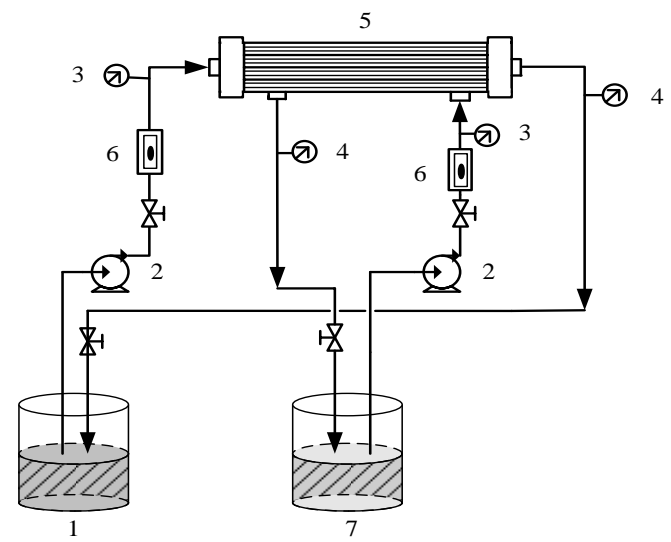

Fig. 2. Schematic counter-current flow diagram for a single-module operation in the HFSLM: 1) feed reservoir 2) gear pumps 3) inlet pressure gauges 4 ) outlet pressure gauges 5) hollow fiber module 6) flow meters and 7) stripping reservoir.

\section{Analytical Instruments}

Palladium sampling analysis, from the aqueous feed and stripping solution phases, was undertaken by an inductively coupled plasma optical emission spectrometer (ICP-OES) by JY 2000, JY JOBIN YVON (HORIBA). The pH values of the feed solution were measured by a professional $\mathrm{pH}$ Meter PP-50.

\section{RESULTS AND DISCUSSION}

\section{A. Influence of Types of Extractants}

From the previous literature reviews, Aliquat 336 [17] and 
Alamine 336 [16], [18] showed high performance in the extraction of $\mathrm{Pd}(\mathrm{II})$. Consequently, these extractants were selected to investigate the selective extraction of $\mathrm{Pd}(\mathrm{II})$ from the feed solution. The experiment was carried out by using a single-module hollow fiber with the mixture of thiourea and $\mathrm{HCl}$ as stripping solution. As shown in Fig. 3, Alamine 336 was the most suitable extractant for the selective extraction of $\mathrm{Pd}(\mathrm{II})$ at $\mathrm{pH} 2$ of the feed solution. This corresponded to the fact that Alamine 336 is a basic extractant which reacts well with anion of $\mathrm{PdCl}_{4}^{2-}$ at $\mathrm{pH} 2$ of feed solution. The previous report was reported by P. P. Sun, M. S. Lee [19], regarding the separation of platinum and palladium from chloride solution by solvent extraction, using Alamine 336 as an extractant. The results indicate that $99.9 \%$ purity of platinum was obtained at the optimizing conditions. However, more steps in the extraction and recovery, high energy consumption are required. Moreover, this system is still suffered from the separation difficulty of aqueous phase and organic phase.

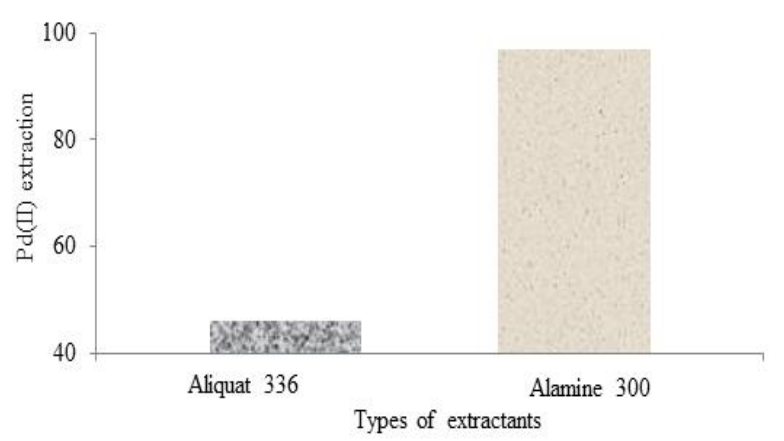

Fig. 3. Percentage of Pd(II) extraction versus types of extractants, using $9 \%$ (v/v) individual extractant concentration.

\section{B. Influence of Types of Stripping Agents}

A number of stripping agents were used for Pd(II) stripping from a complex species. Certainly, the fundamental principle is dependent on the characteristics of the selected extractant. In this work, the investigation of stripping agent influence on Pd(II) stripping from the membrane phase was carried out by testing stripping agents which were able to form complex species with $\mathrm{Pd}(\mathrm{II})$ strong enough to strip $\mathrm{Pd}(\mathrm{II})$ from Alamine 336 chlorocomplex. The stripping agents selected $\mathrm{H}_{2} \mathrm{SO}_{4}, \mathrm{HCl}, \mathrm{NH}_{2} \mathrm{CSNH}_{2}, \mathrm{NH}_{4} \mathrm{Cl}$ and a combination of $\mathrm{NH}_{2} \mathrm{CSNH}_{2}$ and $\mathrm{HCl}$ - were chosen because of their $\mathrm{Pd}(\mathrm{II})$ stripping efficiency. The results as shown in Fig. 4 indicated that the stripping efficiency of $\mathrm{Pd}(\mathrm{II})$ decreased in the order of $\mathrm{NH}_{2} \mathrm{CSNH}_{2}+\mathrm{HCl}>\mathrm{NH}_{4} \mathrm{Cl}>\mathrm{NH}_{2} \mathrm{CSNH}_{2}>\mathrm{HCl}>\mathrm{H}_{2} \mathrm{SO}_{4}$. The combination of $\mathrm{NH}_{2} \mathrm{CSNH}_{2}$ and $\mathrm{HCl}$ achieved a stripping percentage of approximately $70 \%$. This can be attributed to the fact that $\mathrm{NH}_{2} \mathrm{CSNH}_{2}+\mathrm{HCl}$ has stronger decomplexation ability for $\mathrm{Pd}(\mathrm{II})$ compared with other reagents.

\section{Influence of Diluents}

Diluents e.g. hexane, cyclohexane, benzene, 1,2-dichloromethane and chloroform were investigated using Alamine 336 as an extractant via HFSLM in a single operation while keeping the $\mathrm{pH}$ value of the feed solution at 2 . Polarity parameters were taken into consideration in order to select diluents for $\mathrm{Pd}(\mathrm{II})$ extraction and stripping as well as to enhance membrane stability as shown in Table III. As reported in Table III, the extraction and stripping performances of the different kinds of organic diluents was quite high. The results showed that 1, 2-dichloromethane gave the highest percentage of extraction reaching $73.2 \%$, with a relative error of approximately $1.5 \%$.

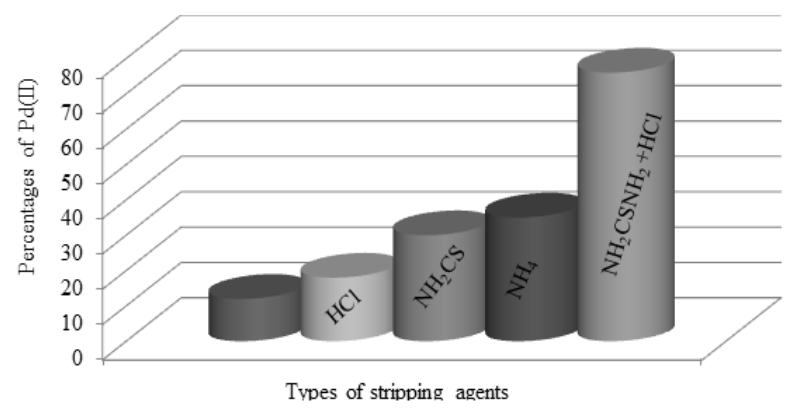

Fig. 4. The influence of the types of stripping agent on the percentage of stripping of $\mathrm{Pd}(\mathrm{II})$ using the concentration of $9 \%(\mathrm{v} / \mathrm{v})$ Aliquat 336

TABLE III: PERCENTAGES OF EXTRACTION AND STRIPPING OF PD(II)

\begin{tabular}{lll}
\hline Diluents & Extraction $(\%)$ & Stripping $(\%)$ \\
\hline Hexane & 70.51 & 61.80 \\
Cyclohexane & 71.78 & 62.64 \\
Benzene & 72.82 & 63.00 \\
1,2-dichloromethane & 73.21 & 66.64 \\
Chloroform & 70.45 & 46.41 \\
\hline
\end{tabular}

\section{Validation of the Method and Analysis of Real Samples}

The separation of $\mathrm{Pd}(\mathrm{II})$ from other metal ions from gold-refining wastewater which contains $\operatorname{Pt}(\mathrm{IV})$, $\mathrm{Au}(\mathrm{III}), \mathrm{Cu}(\mathrm{II})$ and $\mathrm{Zn}(\mathrm{II})$. Under optimum conditions, experimental results indicate that $\mathrm{Pd}(\mathrm{II})$ is selectively extracted by Alamine 336 dissolved in kerosene. On the other hand, $\mathrm{Pd}(\mathrm{II}), \mathrm{Au}(\mathrm{III}), \mathrm{Cu}(\mathrm{II})$ and $\mathrm{Zn}(\mathrm{II})$ were not extracted. Percentages of $\mathrm{Pd}(\mathrm{II})$ extraction and stripping were achieved reaching $95 \%$ and $88 \%$ respectively.

\section{E. Reproducibility of the HFSLM System}

The reproducibility of the HFSLM method, impregnated with Alamine 336 was studied by performing five replicate transport experiments. The relative standard deviation was found to be $\pm 2 \%$. Thus, it can be concluded that HFSLM is an efficient and reliable system for the extraction and stripping of $\mathrm{Pd}(\mathrm{II})$ in chloride media.

\section{Conclusions}

Alamine 336 and a mixture of thiourea and hydrochloric acid were used as an extractan and a stripping agent, respectively. Pd(II) was successfully separated from the feed solution under optimum conditions. Percentages of $\mathrm{Pd}(\mathrm{II})$ extraction and stripping were achieved reaching $95 \%$ and $88 \%$ respectively. Therefore, the HFSLM method can be successfully applied for the extraction and stripping of $\mathrm{Pd}(\mathrm{II})$ from the gold-refining wastewater (GRW).

\section{ACKNOWLEDGEMENT}

The authors greatly appreciate financial support by the Thailand Research Fund through the Royal Golden Jubilee Ph.D. Program (Grant No.PHD/0297/2550). We also thank the Separation Laboratory, Department of Chemical Engineering, and Chulalongkorn University, Thailand, providing support apparatus. 


\section{REFERENCES}

[1] Y. Yamini, M. Moradi, and E. Tahmasebi, "High-throughput quantification of palladium in water samples by ion pair based-surfactant assisted microextraction," Analytica Chimica Acta, vol. 728, pp. 26-30, 2012.

[2] J. Traeger, J. König, A. Städtke, and H.-J. Holdt, "Development of a solvent extraction system with 1,2-bis(2-methoxyethylthio) benzene for the selective separation of palladium(II) from secondary raw materials," Hydrometallurgy, vol. 127-128, pp. 30-38, 2012.

[3] S. Chaturabul, K. Wongkaew, and U. Pancharoen, "Selective transport of palladium through a hollow fiber supported liquid membrane and prediction model based on reaction flux," Separation Science and Technology, vol. 48, pp. 93-104, 2013.

[4] A. Dakshinamoorthy, P. S. Dhami, P. W. Naik, N. L. Dudwadkar, S. K. Munshi, P. K. Dey, and V. Venugopal, "Separation of palladium from high level liquid waste of PUREX origin by solvent extraction and precipitation methods using oximes," Desalination, vol. 232, pp. 26-36, 2008.

[5] V.S. Kislik, "Examples of application of solvent extraction techniques in chemical, radiochemical, biochemical, pharmaceutical, analytical separations, and wastewater treatment," in Solvent Extraction, ch. 5, Elsevier, Amsterdam, 2012, pp. 185-314.

[6] B. Gupta and I. Singh, "Extraction and separation of platinum, palladium and rhodium using cyanex 923 and their recovery from real samples," Hydrometallurgy, vol. 134-135, pp. 11-18, doi: 10.1016/j.hydromet.2013.1001.1001, 2013.

[7] S. Suren, U. Pancharoen, N. Thamphiphit, and N. Leepipatpiboon, "A Generating Function applied on a reaction model for the selective separation of $\mathrm{Pb}$ (II) and $\mathrm{Hg}$ (II) via HFSLM," Journal of Membrane Science, vol. 448, pp. 23-33, 2013.

[8] L. D. Mafu, T. A. M. Msagati, and B. B. Mamba, "The enrichment and removal of arsenic (III) from water samples using HFSLM," Physics and Chemistry of the Earth, Parts A/B/C, vol. 50-52, pp. 121-126, 2012.

[9] N. Sunsandee, P. Ramakul, N. Thamphiphit, U. Pancharoen, and N. Leepipatpiboon, "The synergistic effect of selective separation of (S)-amlodipine from pharmaceutical wastewaters via hollow fiber supported liquid membrane," Chemical Engineering Journal, vol. 209, pp. 201-214, 2012.

[10] R.-S. Juang and H.-L. Huang, "Modeling of nondispersive extraction of binary $\mathrm{Zn}$ (II) and $\mathrm{Cu}$ (II) with D2EHPA in hollow fiber devices," Journal of Membrane Science, vol. 208, pp. 31-38, 2002.

[11] P. Dżygiel and P. P. Wieczorek, "Supported liquid membranes and their modifications: definition, classification, theory, stability, application and perspectives," in Liquid Membranes, S. K. Vladimir Ed. ch. 3, Elsevier, Amsterdam, 2010, pp. 73-140.
[12] P. R. Danesi and P. C. Rickert, "Some observations on the performance of hollow-fiber supported liquid membranes for co-ni separations," Solvent Extraction and Ion Exchange, vol. 4, pp. 149-164, 1986.

[13] A. Kumar, R. Haddad, G. Benzal, R. Ninou, and A. M. Sastre, "Use of modified membrane carrier system for recovery of gold cyanide from alkaline cyanide media using hollow fiber supported liquid membranes: feasibility studies and mass transfer modeling," Journal of Membrane Science, vol. 174, pp. 17-30, 2000.

[14] S. A. Ansari, P. K. Mohapatra, D. R. Raut, M. Kumar, B. Rajeswari, and V. K. Manchanda, "Performance of some extractants used for 'actinide partitioning' in a comparative hollow fibre supported liquid membrane transport study using simulated high level nuclear waste," Journal of Membrane Science, vol. 337, pp. 304-309, 2009.

[15] A. W. Lothongkum, S. Suren, S. Chaturabul, N. Thamphiphit, and U. Pancharoen, "Simultaneous removal of arsenic and mercury from natural-gas-co-produced water from the Gulf of Thailand using synergistic extractant via HFSLM," Journal of Membrane Science, vol. 369, pp. 350-358, 2011.

[16] M. Rovira, L. Hurtado, J. L. Cortina, J. Arnaldos, and A. M. Sastre, "Recovery of palladium(II) from hydrochloric acid solutions using impregnated resins containing Alamine 336," Reactive \& Functional Polymers, vol. 38, pp. 279-287, 1998.

[17] S. D. Kolev, Y. Sakai, R. W. Cattrall, R. Paimin, and I. D. Potter, "Theoretical and experimental study of palladium(II) extraction from hydrochloric acid solutions into Aliquat 336/PVC membranes," Analytica Chimica Acta, vol. 413, pp. 241-246, 2000.

[18] C. Y. Peng and T. H. Tsai, "Recovery of palladium(II) from acidic chloride solution using kerosene containing tri-n-octyl/decyl amine (Alamine 336)," Desalination and Water Treatment, vol. 47, pp. 105-111, 2012.

[19] P. P. Sun and M. S. Lee, "Separation of Pt(IV) and Pd(II) from the loaded Alamine 336 by stripping," Hydrometallurgy, vol. 109, pp. 181-184, 2011.

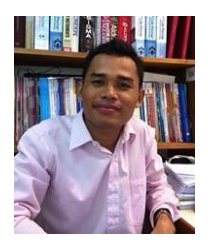

Kraiwith Wongkaew was born in Srisaket, Thailand on May 16 1985. He received his chemical engineering degree at the Ubon Ratchathani University (Thailand) on March 2008. He is currently a PhD candidate of Department of Chemical Engineering, Faculty of Engineering, Chulalongkorn University. His research interests are focused on separation processes, in particular, hollow fiber supported liquid membrane. 